九州大学学術情報リポジトリ

Kyushu University Institutional Repository

A New Replacement Name, Nipponobythus chilisaws for N. Zongicomis Nomura et Lee, 1993 (Coleoptera, Pselaphidae)

Nomura, Shuhe i

Lee, Chang Eon

https://doi.org/10.5109/2595

出版情報 : ESAKIA. 36，pp.60-60，1996-01-31. Entomological Laboratory，Faculty of Agriculture， Kyushu University

バージョン :

権利関係 : 


\title{
A New Replacement Name, Nipponobythus chilisanus \\ for N. Zongicomis Nomura et Lee, 1993 \\ (Coleoptera, Pselaphidae)
}

\author{
Shûhei NOMURA \\ Department of Zoology, National Science Museum (Nat. Hist.), \\ 3-23-1, Hyakunin-chiô, Shinjuku-ku, Tokyo, 169 Japan \\ and \\ Chang Eon LeE \\ 615-2, Hyo Mok 2 Dong, Dong Gu, Taegu, 701-032 Korea
}

The pselaphid species, Nipponobythus longicornis Nomura et Lee, 1993 was described from South Korea on the basis of a male specimen collected at Samjeong Li, Mt. Chilisan. Unfortunetely, this specific name is preoccupied by N. Iongicornis Löbl, 1965 from Chekiang, East China. The authors propose a new replacement name for this species as follows.

\section{Nipponobythus chilisanus nom. nov.}

Nipponobythus fongicornis Nomura et Lee, 1993, Esakia, (33): 15.

\section{References}

Löbl, I., 1965, Beitrag zur Kenntnis der Gattung Nipponobythus Jeanne1 (Col., Pselaphidae). Ann. Naturhistor. Mus. Wien, 68: 491-507.

Nomura, S. and C. E. Lee, 1993, A revision of the family Pselaphidae (Coleoptera) from South Korea. Esakia, (33): 15. 